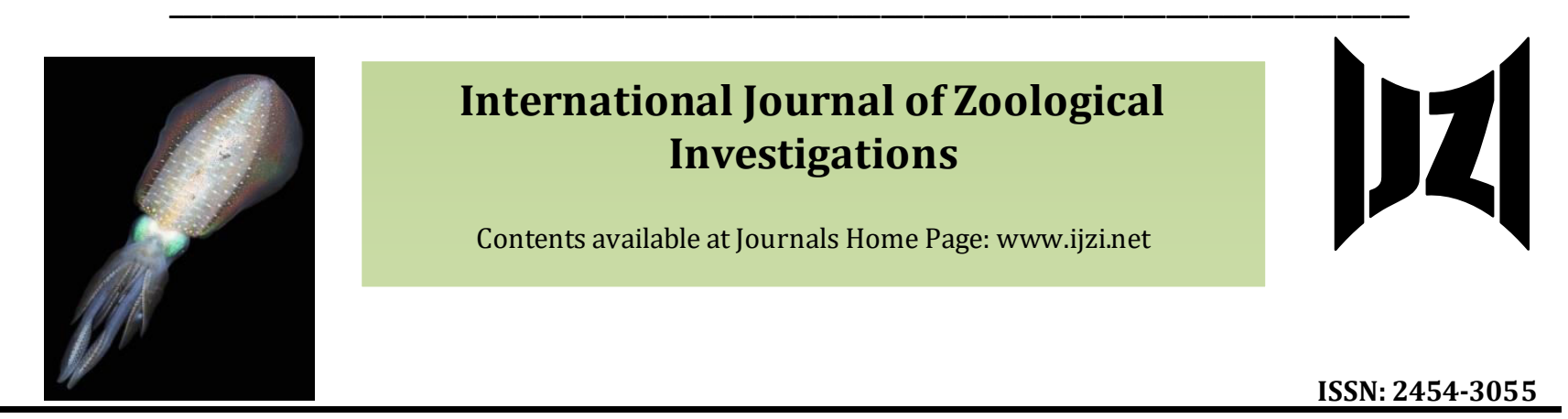

\title{
Identification and Confirmation of Chironomus circumdatus Kieffer, 1916 (Diptera: Chironomidae) Using DNA Barcoding
}

\author{
Rawal Deepak*, Verma Himani and Prajapat Gyata \\ Department of Zoology, Mohanlal Sukhadia University, Udaipur 313001, Rajasthan, India \\ *Corresponding Author
}

Received: 11th May, 2021

Accepted: $4^{\text {th }}$ June, 2021

Published online: $7^{\text {th }}$ June, 2021

https://doi.org/10.33745/ijzi.2021.v07i01.025

\begin{abstract}
Present study was performed to identify and confirm collected larval Chironomid up to species level. To assess molecular taxonomy and phylogeny, DNA barcoding was done using Sanger dideoxy sequencing of mitochondrial cytochrome c oxidase subunit I (COI) gene of larval sample. Bioinformatics analysis was done by using NCBI's BLAST software. By evidence of DNA barcoding, it was confirmed that present larval chironomid species was Chironomus circumdatus Kieffer, 1916.
\end{abstract}

Keywords: Chironomids, DNA barcoding, NCBI, BLAST, COI, Chironomus circumdatus

Citation: Rawal Deepak, Verma Himani and Prajapat Gyata: Identification and confirmation of Chironomus circumdatus Kieffer, 1916 (Diptera: Chironomidae) using DNA barcoding. Intern. J. Zool. Invest. 7 (1): 301-307, 2021. https://doi.org/10.33745/ijzi.2021.v07i01.025

\section{Introduction}

Chironomids are non-biting holometabolous cosmopolitan midges and one of the most abundant dipterans found in all lentic and lotic freshwater ecosystems (Ferrington, 2008). It comprises at least more than 10000 species but roughly more than 6000 are known to us. This family can tolerate wide range gradients of oxygen concentration, $\mathrm{pH}$, salinity and temperature. Chironomids have four life stages (egg, larvae. pupae and adults) with most of their life spent as larval stage
(Armitage et al., 1995). They originated and also have fossil record from Triassic about 248-210 mya. (Cranston et al., 2010). They are found in all zoogeographic regions of the World (Ashe et al., 1987). One of the cryptobiotic sleeping chironomid Polypedilum vanderplanki also shows anhydrobiosis (Cornette et al., 2010; Gusev et al., 2014). Chironomus circumdatus is one of the most common and widespread species of Chironomidae in India (Kumar and Gupta, 
1990). It is also reported from Jaipur, Rajasthan (Sharma and Gupta, 2014). It has four polytene chromosomes $(2 n=8)$ with pseudothummi cytocomplex combination $\mathrm{AE}$, BF, CD and G (Kumar and Gupta, 1990; Chingangbam et al., 2017). Morphological identification of larval chironomids is very hard and taxonomic expertise needed for species identification is lacking. Larval keys usually identify only up to genera level and identification up to species level is only possible by rearing larvae and collecting adults. Thus DNA barcoding seem promising in taxonomic assessment of chironomid community assessment (Failla et al., 2016).

DNA barcoding is a useful and powerful tool for molecular identification and confirmation of unknown and cryptic species at each and every stage of life cycle. It can be performed on monotypic samples consists of either whole or part of an organisms. DNA barcoding generally use a fragment of standard mitochondrial cytochrome c oxidase subunit I gene (COI/COX1) but other genes may also be used (Yong-Yi et al., 2013). This technique uses PCR to amplify a fragment of COI gene with aid of universal primers, which is further sequenced and compared to a database of known organisms. Universal DNA primers (viz. LCO 1490 of 25 bp [5GGTCAACAAATCATAAAGATATTGG-3'] and HCO 2198 of 26 bp [5TAAACTTCAGGGTGACCAAAAAATCA-3`]) are a 710 bp fragment of the mitochondrial cytochrome c oxidase subunit I (COI) gene derived from eleven invertebrate phyla (viz. Annelida, Arthropoda, Cnidaria, Echinodermata, Echiura, Mollusca, Nemertinea, Platyhelminthes, Pogonophora, Sipuncula and Tardigrada). In the code names above LCO refer to light cytochrome oxidase and HCO refer to heavy cytochrome oxidase. The numbers (1490 and 2198) refer to the position of the Drosophila yakuba 5' nucleotide (Folmer et al., 1994). COI gene is generally a closed single circular DNA (Larse et al., 2010). These universal primers were originally designed from three coding and six anticoding strands by comparing highly conserved regions of mitochondrial COI genes across eleven taxa listed above (Sharma and Kobayashi, 2014). Mitochondrial COI gene has been accepted as the standard barcode due to its reliability and robustness (Boehme et al., 2012). However, DNA barcoding also has limitations such as recent speciation, incomplete lineages, interspecific hybridization, infection by endosymbiotic bacteria such as Wolbachia etc. which may negatively affect result of DNA barcoding in insects (Lars et al., 2010; Virgilio et al., 2010).

The present study was performed to identify and confirm up to species level the collected larval Chironomid samples from Jaisamand Lake and Rajsamand Lake, Rajasthan, India.

\section{Materials and Methods}

Larval Chironomid samples were collected from Jaisamand Lake and Rajsamand Lake, Rajasthan, India and carried to the laboratory in plastic bottles. In laboratory identification up to genera level was done under microscope using available taxonomic keys (Epler, 2001). Yet to confirm up to species level, Sanger sequencing of mitochondrial cytochrome $\mathrm{c}$ oxidase subunit I (COI) gene of larval sample was done. For this, larval samples of Chironomus were sent to Dextrose Technologies Laboratory, Bangalore, 
Karnataka. Experimental protocol and methods adopted are as follows:

DNA isolation and extraction:

DNA was isolated from Larval sample using Genei DNA extraction kit. Extracted DNA was eluted in $25 \mu \mathrm{l}$ of nuclease-free water.

PCR amplification using universal primers:

Isolated DNA of larvae was subjected to amplification through forward and reverse DNA sequencing reaction of PCR product was carried out with LCO 1490 (5'-GGTCAAC AAATCATAAAGATATTGG-3') and HCO 2198 (5'TAAACTTCAGGGTGACCA AAAAATCA-3') universal primers in $25 \mu \mathrm{l}$ reaction volume, using thermo cycler (Biorad T100 gradient PCR). Composition of reaction mixture for PCR is given in Table 1 . The PCR was carried out according to the cycle condition mentioned in Table 2 .

Table 1: Composition of reaction mixture for PCR

\begin{tabular}{|c|c|c|}
\hline S. No. & Components & Quantity \\
\hline 1 & $\begin{array}{l}\text { Nuclease free } \\
\text { water }\end{array}$ & $\begin{array}{l}\text { To make up volume for } \\
25 \mu \mathrm{l}\end{array}$ \\
\hline 2 & DNA & 100ng \\
\hline 3 & Primer & $1 \mu \mathrm{l}$ \\
\hline 5 & $\begin{array}{c}\text { 2X PCR Master } \\
\text { Mix }\end{array}$ & $12.5 \mu \mathrm{l}$ \\
\hline 6 & Total Volume & $25 \mu \mathrm{l}$ \\
\hline
\end{tabular}

Quality check of DNA using agarose gel electrophoresis:

The isolated DNA, products were analyzed on $1 \%$ of agarose gel (Fig. 1). The methodology is given below:

- $1 \%$ agarose was prepared in $100 \mathrm{ml}$ 1xTAE buffer and was dissolved by heating.

- It was then, cooled down and ethidium bromide $(10 \mu \mathrm{g} / \mathrm{ml})$ was added.
- Comb and the casting try was set, into that, the molten agarose containing ethidium bromide was pour and was allowed to solidify.

- The DNA (100 ng) was loaded with 6X loading dye, along with 500 bp DNA ladder.

- The resolved DNA was documented through gel documentation system.

Table 2: Thermal cycler reaction condition

\begin{tabular}{|l|c|c|c|c|}
\hline $\begin{array}{l}\text { S. } \\
\text { No. }\end{array}$ & Steps & Temperature & Time & Cycles \\
\hline 1 & $\begin{array}{c}\text { Initial } \\
\text { Denaturation }\end{array}$ & $94 \mathrm{C}$ & $4 \mathrm{~min}$ & 1 \\
\hline 2 & Denaturation & $94 \mathrm{C}$ & $40 \mathrm{sec}$ & \\
\hline 3 & Annealing & $47 \mathrm{C}$ & $40 \mathrm{sec}$ & 35 \\
\hline 4 & Extension & $72 \mathrm{C}$ & $45 \mathrm{sec}$ & \\
\hline 5 & $\begin{array}{c}\text { Final } \\
\text { Extension }\end{array}$ & $72 \mathrm{C}$ & 20 & 1 \\
& \multicolumn{5}{|c}{} & \\
\hline
\end{tabular}

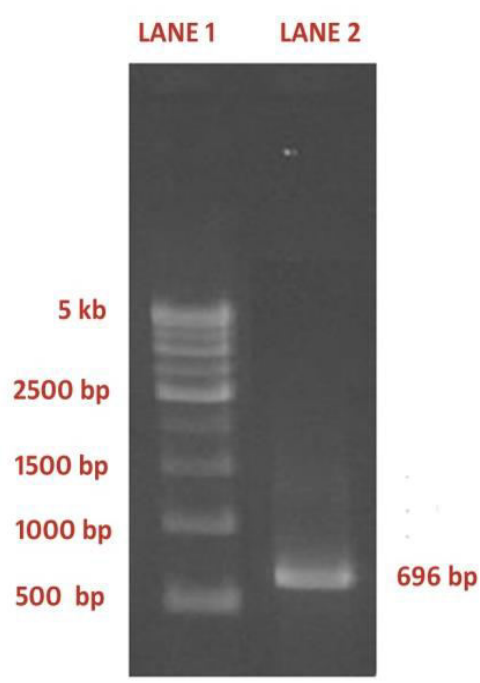

Fig. 1: Gel photograph: (Lane 1. 500 bp DNA Ladder; Lane 2. amplified Sample DNA).

Sanger sequencing of amplicon:

The PCR amplicon was purified enzymatically using Exo-SAP, as per the manufacturer instructions (Applied Biosystem). After the 
purification, the products were subjected to Sanger dideoxy sequencing using following Sequencing Instruments and Chemistry:

- $\mathrm{ABI} 3130$ genetic analyzer

- Chemistry cycle sequencing kit

- $\quad$ Big dye terminator version 3.1

- Polymer and capillary array: POP_7 pol capillary array

- Analysis protocol: BDTv3-KB-Denovo_v 5.2

Bioinformatics analysis:

Bioinformatics and phylogenetic analysis was done by us using NCBI's BLAST software (https://blast.ncbi.nlm.nih.gov/Blast.cgi). BLAST (Basic Local Alignment Search Tool) is an online search and alignment tool for nucleotide sequences provided by NCBI (National Center for Biotechnology Information). It allows us to find regions of similarity between nucleotide sequences. The NCBI maintain a largest genetic sequence database called GenBank; an annotated collection of all publicly available nucleotide sequences. BLAST compares the query sequences to the database in order to find the most similar ones.

\section{Results and Discussion}

Taxonomic species identification of larval chironomids is time consuming and difficult due to morphological similarities in them. Chironomid species identification and confirmation using chromosomes is also not possible due to chromosomal polymorphism amongst members of same species. DNA barcoding using COI gene is useful for species confirmation but due to their abundance and absence of available GenBank database, it is also not feasible for all collected larvae. But in this case we were lucky that database of Chironomus circumdatus is available on GenBank. Without available database we can only conclude up to taxon up to which database is available (Singh and Rawal, 2016a). Genus Chironomus is previously reported from Jaisamand Lake, Fatehsagar Lake, Pichola Lake, Udaisagar Lake and Rajsamand Lake but their species confirmation was not done (Singh and Rawal, 2016b; Verma and Rawal, 2021; Prajapat and Rawal, 2021). FASTA (Faster Alignment) is a text-based format for representing either nucleotide sequences. FASTA (query) sequence of our sample obtained (696 base pairs) is as follows:

TAAACTTCCAGGGTGACCAAAAAATCAAAATAAAT GTTGATAAAGAATAGGGTCTCCACCTCCTGCAGGAT CAAAAAAAGATGTATTTAAATTTCGATCAGTAAGA AGTATAGTAAT AGCTCCTGCTAATACAGGTAAAGA AAGCAAT AGGAGAACAGTAGTAATTACTACTGATC AAACGAAAAGAGGTATTCGATCCAGAGTAATTCCA TTAGCTCGTATATTAATAACTGTAGTAATAAAATT TACTGAACCTAAAATTGATGATACTCCAGCTAAATG TAAAGAAAAAATAGCTAAATCTACAGAAGCCCCAC TATGAGCAATTGCTGCAGAAAGTGGAGGATAAACA GTTCAACCAGTTCCTGCTCCATTTTCTACAAATGAA CTAGAAAGAAGAAGAGTTAAAGAAGGGGGAAGAAG TCAAAAACTTATATTATTTATTCGAGGAAATGCCA TATCTGGTGCTCCTAATATAAGAGGAACAAGTCAA TTTCCGAATCCCCCAATTAAAATAGGTATAACTATG AAAAAAATTATAATAAAAGCGTGGGCTGTAACAAC AACATTATAAATTTGATCATCACCAATGAATGTTCC AGGTCGTCCTAATTCTGCTCGAATAAGCATTCTTAA TGAAGTACCTACTATTCCTGATCATGCTCCAAAAAT AATGTATAATGTTCCAATATCTTT.

Significant sequence similarity alignment (top 10) obtained using BLAST is given in Figure 2 and neighborhood phylogeny tree (at 
Fig. 2: Significant sequence similarity alignment obtained using BLAST.

\begin{tabular}{|c|c|c|c|c|}
\hline Description & Scientific Name & \multicolumn{3}{|c|}{ Query Cover Evalue Per, ident Accession } \\
\hline Chironomus circumdatus isolate LDP1B cytochrome coxidase subunit I (COI) gene, partial ccs'; mitochondriad & Chironomus circumdatus & $91 \%$ & 0 & 99.84 MN934189.1 \\
\hline Chironomus circumdatus isolate EP1H cytochrome coxidase subunit I (COI) gene, partial cds; mitochondrial & Chironomus circumdatus & $82 \%$ & 0 & 99.83 MN934157.1 \\
\hline Chironomus circumdatus isolate EB LG cytochrome coxidase subunit I (CO) gene, partial cds; mitochondrial & Chironomus circumdatus & $91 \%$ & 0 & 99.69 MN934270.1 \\
\hline Chironomus circumdatus isolate MN7 cytochrome c oxidases subunit/ I (COI) gene, partial cds', mitochondrial & Chironomus circumdatus & $91 \%$ & 0 & 99.6910287749 .1 \\
\hline Chironomus circumdatus isolate MN5 cytochrome c oxidases subunit/ (CO) gene, partial cds'; mitochondrial & Chironomus circumdatus & $91 \%$ & 0 & $99.69 J 0287747.1$ \\
\hline Chironomus circumdatus isolate LBBLD cytochrome coxidase subunit | (CO\| gene, partial cds' mitochondrial & ndatus & $90 \%$ & 0 & 34276.1 \\
\hline Chironomus circumdatus isolate PP1D cytochrome coxidase subunit I (CO) gene, partial cdss; mitochondrial & Chirono & $88 \%$ & 0 & 99.68 MNG34206.1 \\
\hline Chironomus circumdatus isolate PP1 H cyttochrome coxidase subunit I (CO) gene, partial cds; mitochondrial & Chironomus circ & $87 \%$ & 0 & 99.67 MN934210.1 \\
\hline Chironomus circumdatus isolate PPI C cytochrome coxidase subunit I (CO) gene, partial cds; mitochondrial & Chironomus circumdatus & $87 \%$ & 0 & 99.67 MN934205.1 \\
\hline Chironomus circumdatus isolate EP1M cytochrome coxidase subunnit / (CO) gene, partial cds; mitochondrial & Chironomus circumdatus & $86 \%$ & 0 & 99.67 MN934162.1 \\
\hline
\end{tabular}

Fig. 3: Neighborhood phylogeny tree obtained using BLAST.

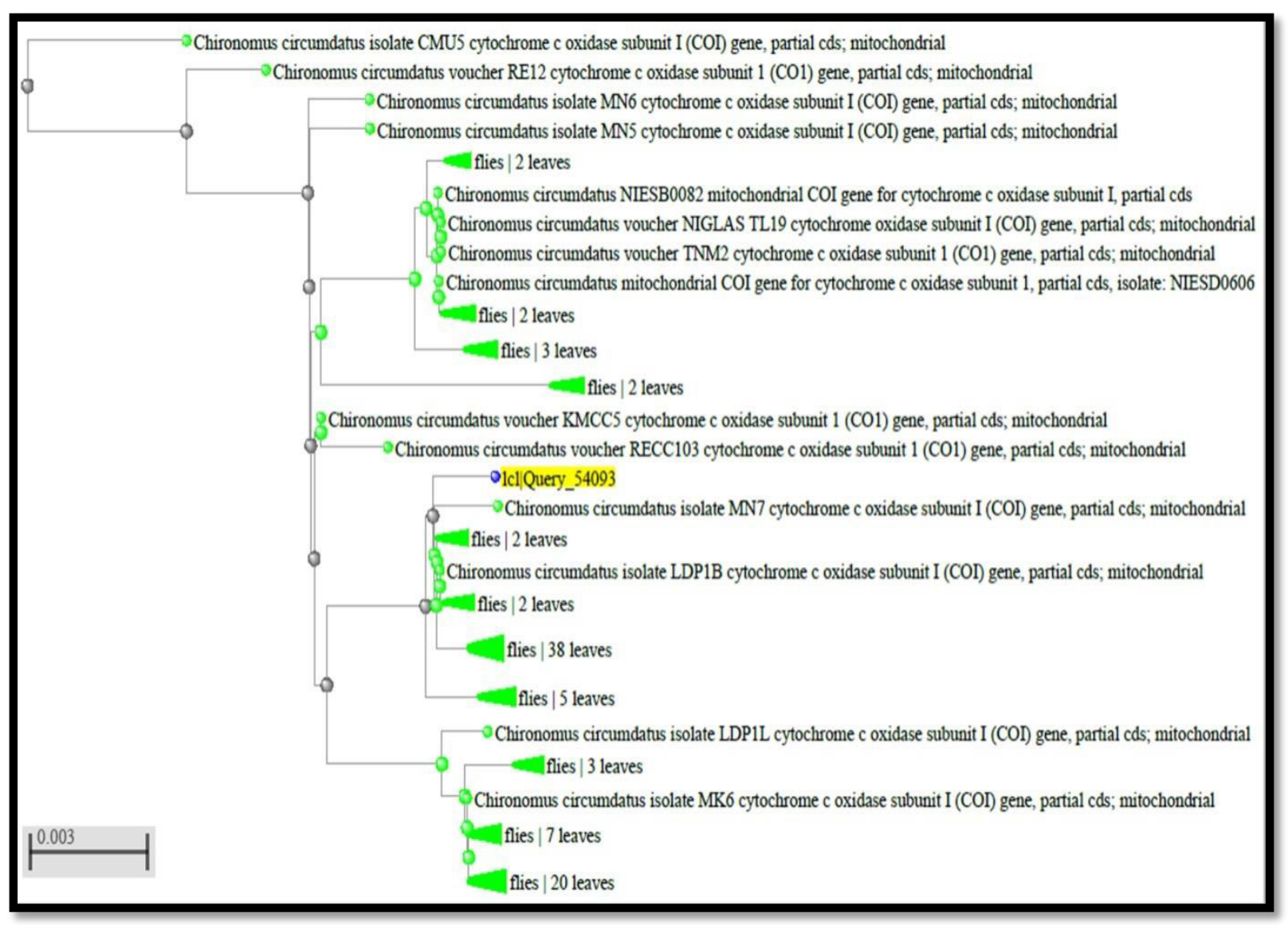

distance scale- 0.004) obtained using BLAST is given in Figure 3. Per cent Identity in our case reported is $99.84 \%$ (Fig. 2). Per cent identity is a number that show how similar the query sequence is to the target sequence. The higher the per cent identity is, the more significant the match. Query cover in our case reported is 91\% (Fig. 2). Query cover is a number that show how much of the query sequence is covered by the target sequence. This tells us 
how long the sequences are relative to each other. E value (expected value) in our case reported is 0.0 (Figure 2). E value is a number that show how many times we would expect a match by chance in a database. The lower the $E$ value is, the more significant the match.

\section{Conclusion}

By evidence of molecular taxonomy and phylogeny concluded by DNA barcoding, we are $99.84 \%$ sure that present sample was of chironomid species named Chironomus circumdatus whose taxonomic classification and hierarchy is as follows:

Domain- Eukaryota/Eukarya; KingdomAnimalia; Subkingdom- Eumetazoa/Metazoa; Clade (unranked) - Bilateria; Clade (unranked) - Coelomata; InfrakingdomProtostomia; Superphylum- Ecdysozoa; Phylum-Arthropoda; Superclass- Hexapoda; Class- Insecta; Subclass- Pterygota; InfraclassNeoptera; Superorder- Endopterygota/ Holometabola; Order- Diptera; SuborderNematocera; Infraorder- Culicomorpha; Superfamily- Chironomoidea; FamilyChironomidae; Subfamily- Chironominae; Tribe- Chironomini; Genus- Chironomus; Species- Chironomus circumdatus Kieffer, 1916.

\section{References}

Armitage PD, Cranston PS and Pinder LCV. (1995) The Chironomidae: Biology and ecology of non-biting midges. $1^{\text {st }}$ ed. Chapman and Hall, London, pp. 1-538.

Ashe P, Murray DA and Reiss F. (1987) The zoogeographical distribution of Chironomidae. Annals Limnol. 23: 27-60.

Boehme P, Amendt J and Zehner R. (2012) The use of COI barcodes for molecular identification of forensically important fly species in Germany. Parasitol Res. 110: 2325-2332.

Chingagbam DS, Wahengbam SD and Haobam I. (2017) Karyo-morphometric studies of Chironomus circumdatus from Manipur, India. J Entomol Zool Stud. 5(4): 1740-1745.

Cornette R, Kanamori Y, Watanabe M, Nakahara Y, Gusev O, Mitsumasu K, Kadono-Okuda K, Shimomura M, Mita K, Kikawada T and Okuda T.. (2010). Identification of anhydrobiosis-related genes from an expressed sequence tag database in the cryptobiotic midge Polypedilum vanderplanki (Diptera; Chironomidae). J Biol Chem. 285 (46): 35889-35899.

Cranston PS, Hardy NB, Morse GE, Puslednik L and McCluen SR. (2010) When molecules and morphology concur: the 'Gondwanan' midges (Diptera: Chironomidae). System Entomol. 35: 636-648.

Epler JH. (2001) Identification manual for the larval Chironomidae (Diptera) of North and South Carolina. $1^{\text {st }}$ ed. North Carolina Department of Environment and Natural Resources Division of Water Quality, USA, pp. 1-526.

Failla AJ, Vasquez AA, Hudson P, Fujimoto M and Ram JL. (2016) Morphological identification and COI barcodes of adult flies help determine species identities of chironomid larvae (Diptera, Chironomidae). Bull Entomol Res. 106 (1): 34-46.

Ferrington L. (2008) Global diversity of non-biting midges (Chironomidae; Insecta-Diptera) in freshwater. Hydrobiol. 595: 447-455.

Folmer O, Black M, Hoeh W, Lutz R and Vrijemnhoek R. (1994) DNA primers for amplification of mitochondrial cytochrome c oxidase subunit I from diverse metazoan invertebrates. Molec Mar Biol Biotechnol. 3 (5): 294-299.

Gusev O, Suetsugu Y, Cornette R, Kawashima T, Maria D L, Kondrashov AS, Penin AA, Hatanaka R, Kikuta S, Shimura S, Kanamori H, Katayose Y, Matsumoto T, Shagimardanova E, Alexeev D, Govorun V, Wisecaver J, MikheyevA, Koyanagi R, Fujie M, Nishiyama T, Shigenobu S, Shibata TF, Golygina V, Hasebe M, Okuda T, Satoh N and Kikawada T. (2014) Comparative genome sequencing reveals genomic signature of extreme desiccation tolerance in the anhydrobiotic midge. Nature Commun. 5: 4784.

Kumar A and Gupta JP. (1990) Cytogenetic studies of Chironomus circumdatus from India (Diptera: Chironomidae). Genetica 82 (1): 157-163.

Lars H, Joan P, Ignacio R and Michael B. (2010) Mitochondrial Cox1 sequence data reliably uncover patterns of insect diversity but suffer from high lineage idiosyncratic error rates. Plos ONE 5 (12): e14448. 
Prajapat G and Rawal D. (2021) Biodiversity assessment of Chironomids (Diptera: Chironomidae) in Rajsamand Lake (Rajsamand, Rajasthan, India). Intern J Zool Invest. 7(1): 90-97.

Sharma MR and Gupta V. (2014). Morphological identification of Chironomus larvae in Jaipur district (Rajasthan) India. Intern J Sci Res. 3: 411-413.

Sharma P and Kobayashi T. (2014) Are "universal" DNA primers really universal? J Appl Gen. DOI 10. 1007/s13353-014-0218-9.

Singh P and Rawal D. (2016) Molecular phylogeny of Einfeldia (Diptera: Chironomidae) inferred from sequencing of mitochondrial cytochrome oxidase subunit 1 (COX1) gene. Int J Entomol Res. 1(6): $11-15$.
Verma H and Rawal D. (2021). Biodiversity analysis of chironomids (Diptera: Chironomidae) in Jaisamand Lake (Udaipur, Rajasthan). Intern J Entomol Res. 6 (2): 135-139.

Virgilio M, Backeljau T, Nevado B and Meyer MD. (2010) Comparative performances of DNA barcoding across insect orders. BMC Bioinform. 11: 206.

Yong-Yi S, Xiao C and Robert WM (2013). Assessing DNA barcoding as a tool for species identification and data quality control. PLOS ONE 8 (2): E57125.

Singh P and Rawal D. (2016) Biodiversity of Chironomidae (Diptera) from Udaipur region (India). Inter J Adv Res. 4 (9): 502-505. 